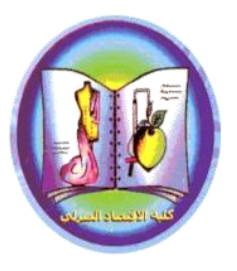

The $7^{\text {th }}$ international- 21 ${ }^{\text {th }}$ Arabic conference for Home Economics

"Home Economics and sustainable development2030"

December -15th, 2020

http://homeEcon.menofia.edu.eg

Journal of Home

Economics

ISSN 1110-2578

\title{
Effect of some Herbs in Improvement of Anemia in Rats
}

\author{
Hamdia, H. Ahmed; Nehad R. El Tahan, Rasha Kamal Ibrahim \\ Abd El Ghany \\ Nutrition and Food Science Dept., Home Economics Faculty, Menoufia \\ University, Egypt.
}

\begin{abstract}
The potential health benefits of mint, ginseng, chamomile and thyme powder as functional food supplement to improve iron 1absorption as well as to prevent and treat anemia associated with deficiency in iron intake were evaluated in rats. Five experimental groups were fed diet supplemented with 5\% tested herbs and 1\%iron gluconate for $4 \mathrm{wk}$ compared with the positive control (free iron). At the end of the experiment, rat groups fed herbs supplemented diets were characterized by significant dose-related increases in the level of serum iron, in addition, there were variable increases in the measured levels of hemoglobin, hematocrit and ferritin in herbs fed groups compared with the control group. Liver functions wasassessedby estimation of plasma concentration of enzymes activities ofaspartateamino transferase (AST), alanineamino transferase (ALT) andlipid fraction (total cholesterol and triglyceride), cholesterol fraction (HDL-c, LDL-c, VLDL-c), Uricacid, Urea nitrogen and glucose .Results showedan improvement in case of tested herbs at the level of 5\% for the above parameters. These data suggested that ginseng followed by chamomile andmint powder could provide with tested parameters and iron absorption and bioavailability of them when incorporated in daily diets and therefore, could be considered as a very effective food supplement to prevent and treat anemia .
\end{abstract}

Key Words: Rats, herbs, iron absorption, anemia .

\section{Introduction}

Iron-deficiency anemia is another global nutritional problem occurring as a complication of nutritional and absorption disorders and is observed frequently over ages (Makrides et al., 2003). Shortage in 
dietary iron intake or absorption represents the major risk factor of the incidence of iron-deficiency anemia . Iron-deficiency has been strongly related with many human diseases including immune disorders (Kim et al.; 2002), chronic inflammation, restriction of physical performance , neurological impairment and cognitive deficits (Kriger and Schroeder 2001).

Most anemia are caused by a lack of nutrients required for normal erythrocyte synthesis, principally iron, vitamin B12, and folic acid. Others results from a variety of conditions such as hemorrhage, genetic abnormalities chronic diseases states, or drug toxicity. The anemia that result from an inadequate intake of iron, protein, certain vitamins (B12,folic acid, pyridoxine, and ascorbic acid), copper, and other heavy metals are frequently called nutritional anemia. The most common nutritional anemia result from iron or folic acid deficiency (Kathleenand sylivia, 2008).

Anemia is a decrease in number of red blood cells (RBCs) or less than the normal quantity of hemoglobin in the blood. It can include a decrease oxygen-binding ability of each hemoglobin molecule due to deformity or lack in numerical development as in some other types of hemoglobin deficiency. Because hemoglobin (found inside RBCs) normally carries oxygen from the lungs to the capillaries, anemia leads to hypoxia (lack of oxygen) in organs (Kundanet al ., 2011).

Anemia can affect the quality of your life by lowering your energy level, making you feel tired and making it difficult to go about your daily activities. Also, anemia is much more easily prevented than corrected. A liberal intake of iron the formative years can go a long way in preventing iron-deficiency anemia. Diet is of the utmost importance in the treatment of anemia. Almost every nutrient is needed for the production of red blood cells, hemoglobin and the enzymes, required for their synthesis. Refined food like white bread, polished rice, sugar, and desserts rope the body of the much needed iron. In addition medicinal plants play an important role in health care as well as in personal care of mankind alongside the therapeutically active substances. Also, herbal drugs are useful in the treatment of various disorders and supports traditional and medicinal value in the society (Dhakaret al.,2012).

Iron gluconate is a type of iron, iron gluconate is used to treat iron deficiency anemia (red blood cell deficiency due to iron deficiency in the body). FerrousGluconate, a drug used in the treatment or prevention of anemia in patients with iron deficiency, due to poor nutrition or iron absorption from the intestines or due to pregnancy and breastfeeding, it is recommended for pregnant women throughout pregnancy and lactation period, $300 \mathrm{mg}$ tablets, manufactured by Julphar(Reznikoff andGoebel, 2015). 
Chamomile is one of the natural herbs used to treat anemia, by adding chamomile to boiled water, then left to cool a little, and is sweetened with honey, and then drink it to treat anemia. Mint is one of the herbs known to all people and has many uses, it can be used to treat anemia, through to mint leaves in water, and drink this drink at least twice a day. Thyme is used in many medical treatments, which can be used twice a day to treat anemia.Ginseng is very powerful for treating anemia, by crushing its seeds and using it as tea (Omoloet al., 2017).

It is important to know that the use of herbs may cause side effects or stimulate the occurrence of these effects, and may interfere with the work of some species, so it is important to pay attention to use only under medical supervision, it should be noted that the use of herbs to treat diseases or strengthen the body needs to duration Long to show results, it is herbs that can be used to treat and control anemia, chamomile, thyme, ginseng and mint (WHO, 2018).

So, this study speculated that tested herbs might have a stimulatory effecton iron absorption. Therefore, the study examined whethertested herbs feeding of rats prevents anemia throughout increase the absorption of iron.

Material and Methods

The mint, ginseng, chamomile and thyme were obtained from the local markets of Menoufia governorate.Gluconate iron were obtained from Elgomhoria Company formed-preparations chemicals and Medical Equipments, Dokki, Egypt. All herbs were grinded into soft herb by using Electric grinder to give a powder and kept in dusky Stoppard glass bottles in a cool and dry location till use according to Russo (2001), Thirty six female albino rats weighing $140 \pm 10 \mathrm{~g}$ were selected from the Institute of Medical Insect Research, Dokki, Egypt.

All rats were fed on basal diet prepared according to American Institute of Nutrition (AIN) (1993) for 7 consecutive days. After this adaptation period, All rats fed on diet free iron and vitamin c. Rats are divided into 6 groups, each group which consists of 6 rats as follows:

* Group (1): Rats implemented on the main meal over the duration of the experiment as a control group

* Group (2): Rats fed on basal diet and 5\%mint + iron gluconate material by $1 \%$

* Group (3): Rats fed on basal diet and 5\% chamomile + iron gluconate material by $1 \%$

* Group (4): Rats fed on basal diet and5\% ginseng + iron gluconate material by

$1 \%$

* Group (5): Rats fed on basal diet and 5\% thyme + iron gluconate material by $1 \%$ 
* Group (6): Rats fed on basal diet andCombination of (thyme + mint + ginseng + chamomile) by $5 \%+$ iron gluconate material by $1 \%$

By the end of theexperimental periods (28 days),rats were scarified using diethyl ether anesthesia at fasting state .

Part of the blood was taken to determine the level of serum glucose and other portion of blood samples was collected and allowed tocoagulate at room temperature; other portion of blood was added toit,EDTA (ethylenediaminetetraceticacid) and centrifuged at 3000r.p.mfor 15 minutes. Serum was carefullyaspirated and transferred into cleancovettubes and stored frozen at $-20^{\circ} \mathrm{Cuntilthe}$ time of analysis.

Biochemical analysis:

SerumAlkaline phosphatase (ALP)was determined according tothe procedure of Aspartateaminotransferase(AST) or (GOT)glutamic oxaloacetictransaminaseandglutamicpyruvictransaminase(GPT)

orAlanineaminotransferase (ALT)werecarried out according to the method of Henry(1974).Serum uric acid was determined according to the method described by Fossatiet al. (1980).Serum urea in plasma was determined according to the enzymatic method ofPatton and Crouch (1977).Blood was collected by tail venous puncture every week during the experimental period. Hemoglobin was determined according toDrabkin, (1949). Hematocrit was measured using a heparinized tube according toMc-Inory procedure (1954).

Using the serumsamples obtained on the final day of the experiment, serumand total iron binding capacity (TIBC) were determined bymeans of commercial assay kits (Sigma Diagnostic, St. Louis) according to Cavill's method (1986). Hemoglobin regenerationefficiency (HRE) were calculated according to the method and equations of Miller (1982).

Statistical analysis:

Data were analyzed using one-way analysis of variance (ANOVA) followed by the student t-test for significant difference. Statistical significant difference was defined as $\mathrm{P}<0.05$ (Snedecor and Cochran 1976).

Results.

1-Effect of tested plants on feed intake (FI), body weight gain percentage (BWG \%) and feed efficiency ratio (FER) of rats with anemia

Data in table (1) showed the effect of tested plants on feed intake (FI), body weight gain percentage (BWG \%) and feed efficiency ratio (FER\%) of rats fed with anemia. For body weight gain percentage (BWG \%), it could be observed positive control group was signicantlly the lowest group. There are nonsignicant changes among G4, G5 and G6, whereas these groups were signicantlly higher than G2 and G3. 
For feed intake (FI), it could be observed positive control group was signicantlly the lowest group. There are no signicant changes among G4, G5 and G6, whereas these groups were signicantlly higher than G2 and G3.

For feed efficiency ratio (FER),it could be observed positive control group was signicantlly the lowest group, but G2was signicantlly the lower group than G3, G4, G5 and G6. There are no signicant changes among G3, G5 and G6, whereas these groups were signicantlly higher than G4.

Table (1) Effect of tested plants on feed intake (FI), body weight gain percentage (BWG \%) and feed efficiency ratio (FER) of rats with anemia

\begin{tabular}{|c|c|c|c|}
\hline Groups & $\begin{array}{c}\text { Body weight } \\
\text { g/d }\end{array}$ & $\begin{array}{l}\text { Feed } \\
\text { Intake } \\
\text { g/d }\end{array}$ & $\begin{array}{c}\text { Feed efficiency } \\
\text { radio } \\
\text { g /day }\end{array}$ \\
\hline $\begin{array}{l}\text { Positive control (G1) (rats } \\
\text { with Anemia) }\end{array}$ & $9.2^{\mathrm{d}} \pm 0.12$ & $5.8^{\mathrm{d}} \pm 1.33$ & $0.057^{c} \pm \mathbf{0 . 0 0 3}$ \\
\hline Anemia + mint(G2) & $14.7^{\mathrm{c}} \pm 0.13$ & $7.7^{\mathrm{c}} \pm 1.22$ & $0.068^{b} \pm 0.002$ \\
\hline Anemia + chamomile (G3) & $16.7^{\mathrm{b}} \pm 1.90$ & $9.5^{\mathrm{b}} \pm 0.12$ & $0.063^{\mathrm{a}} \pm 0.001$ \\
\hline Anemia + ginseng(G4) & $17.5^{\mathrm{a}} \pm 0.12$ & $10.9^{a} \pm 0.48$ & $0.057^{\mathrm{C}} \pm 0.001$ \\
\hline Anemia + thyme (G5) & $17.5^{\mathrm{a}} \pm 2.11$ & $10.7^{\mathrm{a}} \pm 1.67$ & $0.058^{\mathrm{a}} \pm 0.002$ \\
\hline Anemia + mixture (G6) & $18.2^{\mathrm{a}} \pm 1.22$ & $10.9^{\mathrm{a}} \pm 0.37$ & $0.060^{\mathrm{a}} \pm 0.004$ \\
\hline
\end{tabular}

Means under the same column bearing different superscript letters are different significantly $(\mathbf{p} \leq \mathbf{0 . 0 5})$

\section{Effect of tested plants on liver enzymes (AST, ALT and ALP) of rats with anemia}

Data in table (2) showed the effect of tested plants on liver enzymes (AST, ALT and ALP) of rats fed with anemia. For AST, positive control group was signicantlly higher than G2, G3, G4, G5 and G6 groups, but G6 group was signicantlly Lower than G3,G4,G5 and G6. There are no changes among G2 and G5, whereas these groups were signicantlly higher than G3, G4 and G6. Alsothere are no signicant changes among G3 and G4.

For Alt, it could be observed positive control group was signicantlly higher than G2, G3, G4, G5 and G6 groups, and G2 group wassignicantlly higher than G3, G4, G5 and G6 groups. There are no signicant changes among G3, G5 and G6 groups, whereas these groups were signicantlly lower than G2 and G5. 
For ALP, it could be observed positive control group was signicantlly higher than G2, G3, G4, G5 and G6 groups. There are no signicant changes among G2, G3, G4, G5 and G6.

Table (2) Effect of tested plants on liver enzymes (AST, ALT and ALP) of rats with anemia

\begin{tabular}{|c|c|c|c|}
\hline Groups & AST (U/L) & ALT (U/L) & $\operatorname{ALP}(\mathrm{U} / \mathrm{L})$ \\
\hline $\begin{array}{l}\text { Positive control (G1) (rats } \\
\text { with Anemia) }\end{array}$ & $81.4^{\mathrm{a}} \pm 2.04$ & $76.6^{\mathrm{a}} \pm 6.05$ & $6.4^{\mathrm{a}} \pm 1.13$ \\
\hline Anemia + mint(G2) & $71.3^{b} \pm 2.31$ & $69.5^{b} \pm 1.43$ & $5.2^{\mathrm{b}} \pm 2.36$ \\
\hline Anemia + chamomile (G3) & $64.9^{c} \pm 0.12$ & $50.7^{\mathrm{d}} \pm 2.13$ & $5.3^{b} \pm 1.13$ \\
\hline Anemia + ginseng(G4) & $64.8^{c} \pm 5.13$ & $53.9^{\mathrm{d}} \pm 6.34$ & $5.1^{b} \pm 0.22$ \\
\hline Anemia + thyme (G5) & $71.1^{b} \pm 3.46$ & $64.4^{\mathrm{c}} \pm 4.88$ & $5.4^{b} \pm 0.16$ \\
\hline Anemia + mixture (G6) & $54.6^{\mathrm{d}} \pm 1.85$ & $50.7^{\mathrm{d}} \pm 7.67$ & $5.0^{b} \pm 0.09$ \\
\hline
\end{tabular}

Means under the same column bearing different superscript letters are different significantly $(\mathbf{p} \leq \mathbf{0 . 0 5})$

Effect of tested plantson kidney functions $(\mathrm{mg} / \mathrm{dl})$ of rats with anemia Data in table (3) showed the effect of tested plants on kidney functions of rats with anemia. For creatinine observed positive control group was signicantlly higher than G2 group, and also G2 group was signicantlly higher than G3, G4, G5 and G6. There are no signicant changes among G3, G4, G5 and G6.

For Uric acid, it could be observed positive control group was signicantlly higher than G3, G4, G5 and G6 groups, and also G2 group wassignicantlly higher than G3, G4, G5 and G6 groups. There are no signicant changes among G3, G4, G5 and G6 groups.

Table (3) Effect of tested plantson kidney functions (mg/dl)of rats with anemia

\begin{tabular}{l|c|c}
\multicolumn{1}{c|}{ Groups } & Creatinine & Uric acid \\
\hline $\begin{array}{l}\text { Positive control (G1) (rats with } \\
\text { Anemia ) }\end{array}$ & $\mathbf{2 . 3 2}^{\mathrm{a}} \pm \mathbf{0 . 9 8}$ & $\mathbf{3 . 9}^{\mathrm{a}} \pm \mathbf{3 . 1 7}$ \\
\hline Anemia + mint(G2) & $\mathbf{1 . 6 1}^{\mathrm{b}} \pm \mathbf{0 . 0 1}$ & $\mathbf{3 . 3}^{\mathrm{a}} \pm \mathbf{1 . 2 3}$ \\
\hline Anemia + chamomile (G3) & $\mathbf{0 . 9 0 ^ { \mathrm { c } } \pm \mathbf { 0 . 0 3 }}$ & $\mathbf{2 . 0 ^ { \mathrm { b } } \pm \mathbf { 0 . 0 7 }}$ \\
\hline Anemia + ginseng(G4) & $\mathbf{0 . 6 2}^{\mathrm{c}} \pm \mathbf{0 . 1 1}$ & $\mathbf{1 . 6}^{\mathrm{b}} \pm \mathbf{1 . 2 7}$ \\
\hline Anemia + thyme (G5) & $\mathbf{0 . 6 3}^{\mathrm{c}} \pm \mathbf{0 . 3 6}$ & $\mathbf{1 . 6}^{\mathrm{b}} \pm \mathbf{0 . 8 5}$ \\
\hline Anemia + mixture (G6) & $\mathbf{0 . 6 2}^{\mathrm{c}} \pm \mathbf{0 . 1 2}$ & $\mathbf{1 . 7}^{\mathrm{D}} \pm \mathbf{2 . 3 7}$ \\
\hline
\end{tabular}

Means under the same column bearing different superscript letters are different significantly $(p \leq 0.05)$ 


\section{Serum minerals concentration and hemoglobin indices in rats fed} control and herbs containing diets for 4 weeks.

Data shown in table (4) indicate that all of the assessed serum mineral (iron) were significantly $(\boldsymbol{P}<0.05)$ increased as affected by ginseng, chamomile, mint and thyme intake in a dose-dependent fashion whentested herbs intake level was 5\%. In addition, all serum levels of hemoglobin were also elevated in the range of $12.35 \pm 1.11,13.15 \pm 2.36$ and $14.25 \pm 1.1 \mathrm{~g} / \mathrm{L}$ respectively. While, ferritin was increased in the range of $57.10 \pm 0.36,62.3 \pm 0.1$ and $65.12 \pm 0.15 \mu \mathrm{g} / \mathrm{L}$ respectively. Hemoglobin regeneration efficiency (HRE) was increased at the range of $0.15 \pm 0.05,0.16 \pm 0.02$ and $0.18 \pm 0.01$. Hematocrit was increased at the ranges of $40.25 \pm 1.3,41.15 \pm 2.11$ and $42.15 \pm 1.27 \%$ in the experimental rats fed $2.5,5.0$ and $10.0 \mathrm{mg} / \mathrm{kg}$ diet lactoferrin respectively.

Hemoglobin regeneration efficiency (HRE) in the herb -fed rats was significantly higher than that of the control rat group in a dosedependent fashion while, total iron binding capacity (TIBC) in the herb fed rats was significantly lower than that of the control rat group in a dose- dependent fashion.

Table 4 -iron Serum minerals concentration and hemoglobin indices in rats fed control and herbs containing diets for 4 weeks.

\begin{tabular}{l|l|l|l|l}
\hline Serum Profile & Control diet & $\begin{array}{l}\text { Basal diet with } \\
10 \% \text { cumin }\end{array}$ & $\begin{array}{l}\text { Basal diet with } \\
10 \% \text { ginger }\end{array}$ & $\begin{array}{l}\text { Basal diet with } \\
10 \% \text { Saffron }\end{array}$ \\
\hline Serum Fe $(\mu \mathrm{g} / \mathrm{dl})$ & $69.11 \pm 4.55$ & $76.30 \pm 2.10^{\mathrm{a}}$ & $80.25 \pm 4.10^{\mathrm{b}}$ & $84.30 \pm 2.12^{\mathrm{c}}$ \\
$\mathrm{HRE}^{1}$ & $0.14 \pm 0.01$ & $0.15 \pm 0.05^{\mathrm{a}}$ & $0.16 \pm 0.02^{\mathrm{b}}$ & $0.18 \pm 0.01^{\mathrm{c}}$ \\
$\begin{array}{l}\text { Serum ferritin } \\
(\mu \mathrm{g} / \mathrm{L})\end{array}$ & $49.55 \pm 2.25$ & $57.10 \pm 0.36^{\mathrm{a}}$ & $62.30 \pm 0.10^{\mathrm{a}}$ & $65.12 \pm 0.15^{\mathrm{b}}$ \\
TIBC $(\mu \mathrm{g} / \mathrm{dl})^{2}$ & $345.10 \pm 6.20$ & $339.5 \pm 33.50^{\mathrm{a}}$ & $330.6 \pm 25.55^{\mathrm{a}}$ & $321.7 \pm 10.50^{\mathrm{b}}$ \\
Hemoglobin $(\mathrm{g} / \mathrm{L})$ & $39.15 \pm 0.15$ & $41.15 \pm 2.11^{\mathrm{a}}$ & $41.15 \pm 2.11^{\mathrm{a}}$ & $42.15 \pm 1.27$ \\
Hematocrite $(\%)$ & & & & \\
\hline
\end{tabular}

Means under the same column bearing different superscript letters are different HRE $^{1}$ : Hemoglobin regeneration efficiency, TIBC ${ }^{2}$ : total iron-binding capacity. 


\section{Discussion.}

Anemia is considered as one of the most common index of malnutrition over the world and is caused by iron deficiency store (IDS) or iron-deficiency erythropoiesis (IDE) based on the screening criteria for iron-deficiency anemia (Lin et al., 2009).

In this study, the primary cause of anemia wasconsidered to be the feeding on iron-deficient diet (malnutrition) for a long period (3 weeks) through the adaptation feeding course before incorporation of herbs together with normal load of iron into the experiment diets. The hemoglobin concentration decreased constantly during the feedingperiod of iron-free diets in all the rat groups. It was evident that iron deficiency contributed to thisanemia, because typical signs of iron-deficiency anemia suchas decreases in hemoglobin and serum iron concentrations, andincreases in total iron binding capacity wereobserved (Baynes and Bothwell 1990).

Several authors have reported that iron mal-absorption is mainly caused by some of the food constituents which can be inhibitors of iron absorption and may contribute to the high prevalence of iron deficiency found.Our data indicate that iron gluconate with tested herbs"-feeding prevented the development of anemia and improved hemoglobin, the hematocrit and both serum and bone iron contents in a dose-dependent manner. The final hemoglobin concentration and hematocrit in the ratsfed ginseng were significantly higher than those in the rats fed the control diet. Serum iron and HRE also significantlyincreased after lactoferrin-feeding. It has been reportedthat there was a high positive correlation between serum iron concentrationand iron absorption (Kim and Atallah 2009). Buchowskiet al. (2013)also reported a correlation betweenHRE and apparent absorption of iron. Feeding ginseng and chamomile containingdiet appears to increases in total iron binding capacity as shown in our results.

The present data illustrate that ginseng and chamomile improves both kidney function and liver functions (Khire, 2018).

In the present study, ferric pyrophosphate was used,which is a water-insoluble compound, as the iron source of theexperimental diets. In this case, ginseng feeding is highly suggested to decreasethe $\mathrm{pH}$ of the cecal contents and therefore increases the iron concentrationin the 
soluble fraction of the cecal contents. The mechanism of iron absorptionvia not only the small intestine, but also via the large intestinehas not yet been clarified (Hateo et al., 2017). However, sufficient iron is absorbedvia the large intestine for recovery from irondeficiency anemiain rats (Ebihara et al. 2015 ). Therefore,this study speculate that the effect of the tested herbs in increasing the absorptionof iron takes place in the large intestine in rats.

There are otherpossible explanations for the stimulatory effect of chamomile on ironabsorption in the experimental rats. Thus, lactoferrin might lead to changethe intestinal mucin composition and thereby increase iron absorption in thesmall intestine. Jose and Antonio ( 2014) proposed that the pathwayof iron transport in the intestine consisted of several iron-bindingproteins including mucin, integrin, mobilferrin and ferritin.Once the iron-mucin complex is formed, it keeps the iron in asoluble form after alkalinization in the lumen and thereby facilitatesiron absorption. Second the increase in iron absorption might be dueto the increase in calcium absorption that results from chamomile-feeding.

It could be speculated that mint could stimulateiron absorption via a route independent of iron absorption, suchas the paracellular route, thus, saffron-feeding might reduce the inhibitoryeffect of calcium on iron absorption.

They reported that rat fed soybean as a mint-rich source resulted in significant increase in calcium and iron absorption. On the other hand, as regards the heme production, fermentation could stimulate it by producing the propionate salts, which promote aminolevulinate synthesis that affects heme production and synthesis (Sheng et al., 2016).

In conclusion, 5\% ginseng, chamomile and mint supplementation could completely prevent anemia and improves iron absorption through anemia rats. 


\section{References}

AIN. American Institute of Nutrition. (1993): Purified diet for laboratory Rodent, Final report. J. Nutrition. 123:1939-1951. and O. compactumeBenth. J. essential oil Res. 8 (6): 657-664.

Baynes, R. D. and Bothwell, T. H. (1990): Irondeficiency. Annu. Rev.Nutr. 10:133-148

Buchowski, M. S.; Mahoney, A. W. and Kalpalathika, M. P. V. (2013):Nonhemeiron absorption, apparent iron absorption and hemoglobin regenerationefficiency in anemic and normal rats fed with dietary heme andnonheme iron at various levels,Nutr.Res, 9:773-783.

Cavill, I.; Jacobs, A. and Worwood, M. (1986): Diagnostic methods for iron status. Annu. Clin. Biochem. 23: 168.

Drabkin, D. L. (1949): The standardization of hemoglobin measurement. Am. J. Med. Sci. 217-710.

Dhakar.;Katare. R.; Kumar, Y.; Umesh, P. and Pawar, K. R. (2012): In vivo assessment of bioactivity of TrichosanthesdioicaRoxb for the management of haemolytic anemia. International Journal of Pharm. Tech. Research; 4(2):689-699.

Ebihara, K.; Okano, J. and Miyata, T. (2015): Comparisonof ferrous and ferric iron bioavailability following rat cecalinfusion. Nutr. Res., 14:221-228.

Fassati, P.; and Prencipe, L. (1982): Triglyceride enzymatic colorimetric method. J. of Clin. Chem., (28): 2077.

Henry,R.J. (1974): Clinical Chemistry Principal and Techniques. Harper and Publisher. New York.

Jose, A.; Kumar, S. S and Mukkadan, J.K. (2013): A study on antidiabetic effect of peppermint in alloxan induced diabetic model of Wister rats J. Cline. Biomed. Sci. ; 3 (4): 177-81.

Kim, M. and Atallah, M. T. (2009): Intestinalsolubility and absorption of ferrous iron in growing rats areaffected by different dietary pectins. J.Nutr. 123:117-124.

Kim, S. h.; Kim, H. Y.; Kim, W. K. and Park, O. J. (2002): Nutritional status, iron-deficiency-related indices, and immunity of female atheletes. Nutrition 18(1): 86-90. 
Kathleen M, and Sylivia, E. (2008): Krause's food and Nutrition Therapy, Edition 12.

Kriger, J. and Schroder, C. (2001): Iron, brain and restless leg syndrome. Sleep Med. Rev. 5 (4): 277-286.

Kundan, P.; Mithilesh, P. and Parthiv, C.(2011): A review on anemia. International Journal of Comprehensive Pharmacy. Pharmacy College Rampura, India, (2):1-6.

Lin XM, Wang Z, Shen XY, Long Z, Liu WJ, Guo YM, Tang Y. (2009): Iron status and effect of early iron supplementation on sub-clinical iron deficiency in rural school-age children from mountainous areas of Beijing (China). Zhonghua Yu Fang Yi XueZaZhi. 37(2):115-8.

Makrides, M.; Crowther, C. A.; Gibson, R. A.; Gibson, R. S. and Skeaff, C. M. (2003): Efficacy and tolerability of low-dose iron supplements during pregnancy: a randomized controlled trial. Am. J. Clin. Nutr. 78(1):145-53.

Mc-Inory (1954): A micro hematocrit for determining the packet cell hemoglobin concentration on capillary blood. J. Clin. Path. 7:32.

Miller, J. (1982): Assessment of dietary iron availabilityby rat $\mathrm{Hb}$ repletion assay. Nutr.Rep. Int. 26:993-1005

Omolo O.J.; Chhabra, G. and Nyagah (2017): Determination of iron content in different parts of herbs used traditionally for anaemia treatment in East Africa. J. Ethnopharmacol. 58 97102.

Patton. C.J. and Croush, S.R. (1977): Enzymatic Determination of Urea. J. Anal. Chem. 49: 464-469.

Russo, E. (2001): "Hand book of Psychotropic Herbs A scientific Analysis of Herbal Remedies for Psychiatric conditions". The Howrth Herbal press. Inc.

Reznikoff, P.and Goebel, W. F. (2015): "The Use of Ferrous Gluconate in the Treatment of Hypochromic Anemia". Journal of Clinical Investigation. 16 (4): 547-54.

Snedecor, G. W. and Cochran, W. G. (1976): Statistical Methods. $6^{\text {th }}$ Edn. Ames, Iowa states Univ. Press: 298.

WHO (World Health Organization) (2018): Monographs on selected medicinal plants. WHO., Geneva. of Nutrition.,72(6): 124-1453. 


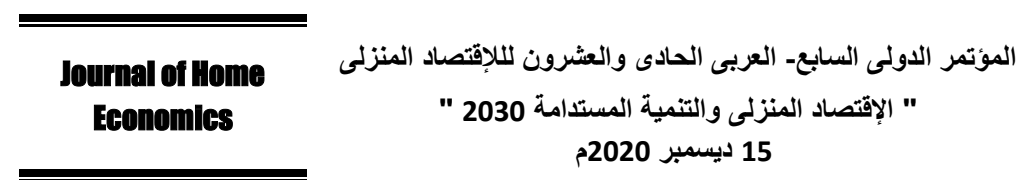

http://homeEcon.menofia.edu.eg

ISSN 1110-2578

دراسة تأثير بعض خلطات الأعشاب النباتية مع أو بدون إضافة مادة جلوكونات

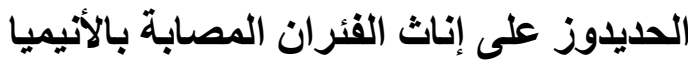

حمدية أحمد هلال ، نهاد رشاد الطحان ، رشا كمال ابراهيم

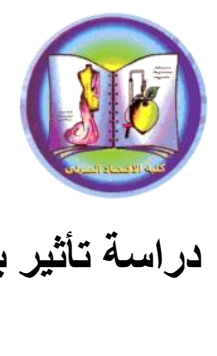

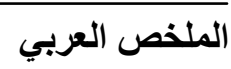

تم تقييم الفو ائد الصحية المحتملة للنعنـاع ، الجينسنج ، البابونج ومسحوق الزعتر

كمكل غذائي وظيفي لتحسين امتصاص الحديد وكذللك لمنع و علاج فقر الدم المرتبط بنقص في تهي

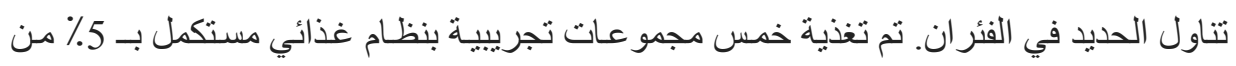
الأعشـاب المختبرة و 1\% جلوكونـات مـن الحديد لمدة 4 أسـابيع مقابل مجموعـة الفئر ان التي

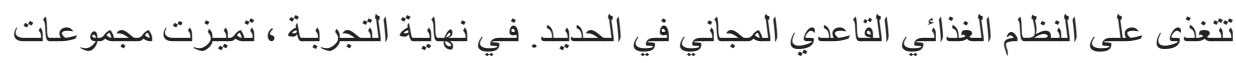

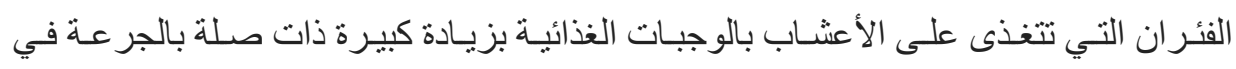

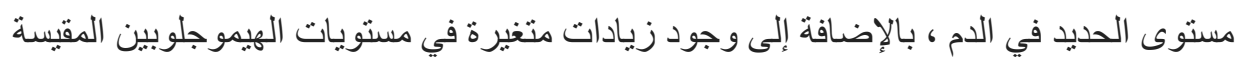
و الهيماتوكريت و الفيريتين في مجمو عات التغذية بالأعشاب في أزياء تعتمد على الجر عة مقارنة

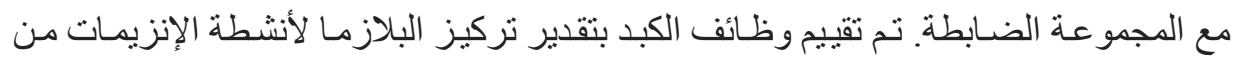

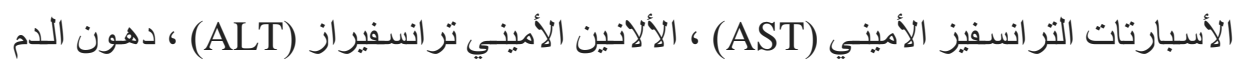

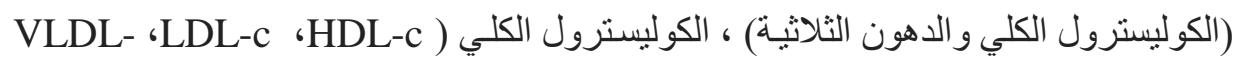

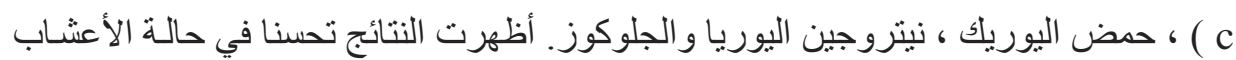
المختبرة عند مستوى 5\% للمعلومات المذكورة أعلاه. هذه البيانات تثـير إلى أن الجينسنج تليها

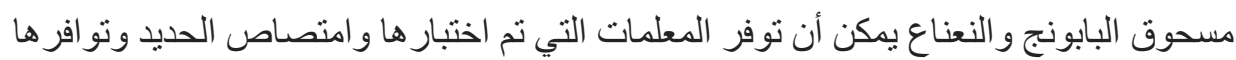
الحيوي عند خلطها في الوجبات الغذائية اليومية ، وبالتالي ، يمكن اعتبار هـا مكملا غذائياً فعال للغاية لمنع و علاج فقر الدم. 